\title{
Fault Sampling of Complex System Under Imperfect Maintenance
}

\author{
http://dx.doi.org/10.3991/ijoe.v9i4.2819 \\ Chao Zhang and Linhan Guo \\ Beijing University of Aeronautics and Astronautics, Beijing, China
}

\begin{abstract}
When conducting simulation for evaluating complex system reliability or availability, stochastic fault sample method is applied to simulate fault occasions of complex system. Current research of fault sample method generally assumes maintenance activity restores systems to "good-as-new" and "bad-as-old", however, system usually keeps its function through imperfect maintenance that restores system to "partly good" in reality. A stochastic fault sample method for availability evaluation for complex system under imperfect maintenance based on monte-carlo simulation principle is proposed. Firstly, single component fault occurrence process subjected to imperfect maintenance is analyzed and the formula for fault occurrence occasion is given. Secondly, fault sample becomes complicated when maintenance object converts to system with complex reliability structure. Not only fault occurrence occasions but also fault components in the system should be derived from the sample method. Fault sample for parallel system is especially difficult, so the Markov state transition process is embedded into the method to solve this problem .Finally, a numerical case using fault sampling method under imperfect maintenance is given and the number of faults and their occurrence time are obtained . Validity and feasibility of the proposed method is verified.
\end{abstract}

Index Terms-Complex system, imperfect maintenance, stochastic fault sample, monte-carlo..

\section{INTRODUCTION}

When conducting simulation for evaluating complex system reliability or availability, method of random sampling is applied to simulate fault occasion of complex system. Complex system fault sampling is referred to simulating the fault occasion according to random numbers and system fault distribution function and determining malfunctioned components according to the system structure and component failure rates relationships.

Maintenance effect can be divided into three kinds: perfect, non-perfect effect and imperfect effect. A perfect effect can restore the component to good-as-new, a noneffect to bad-as-old, and an imperfect effect to partly good. Since it is usually assumed that maintenance effect is partly good in reality, so fault sample method considering imperfect maintenance is more applicable to engineering. At the current stage, research mainly focuses on the imperfect maintenance model, not referring to the fault sampling method under imperfect maintenance. Imperfect maintenance model is discussed in detail in [1][5]. Ref[6] have investigate the system fault sample method, but most of them can't be realistic for they have many constraints. Maintenance condition is always considered as perfect when conducting the fault sampling, it can't be applied for the situation when maintenance is imperfect. Ref[7]-[8] make researches on fault sample method under imperfect maintenance, but hypothesis about life distribution of the system is always deemed exponential, but in reality, life distribution is arbitrary. Ref[9]-[11] make a progress by supposing the system failure rate is time-variant, but they didn't take system structure into consideration. Ref[12] study fault sample method considering system structure, but they generally deem system structure as series, they didn't consider system with complex structure. For the constraints above, fault sample method

In this paper, stochastic fault sample method for system with complex reliability structure under imperfect maintenance is studied according to monte-carlo simulation principle. The novelty of the method stems from the facts that not only the maintenance is imperfect, but also failure rate of components in system is timevariant and. On the basis mentioned above, a flowchart of fault sample method is presented and this flowchart can be applied for system with complex reliability structure. When conducting fault sampling for parallel system, determination of fault components becomes especially difficult, the Markov state transition process is used to solve this problem. Via the fault sampling method, fault occasions of a complex system under imperfect maintenance can be simulated and fault components in the complex system can be determined.

\section{COMPONENT FAULT SAMPLE UNDER IMPERFECT MAINTENANCE}

Maintenance effects can be perfect, non-perfect and imperfect. Time-variant functions of component failure rate corresponding to the maintenance effects are different.

After imperfect maintenance, failure rate of component should situate between the level of "good-as- new" and "bad-as-old". Failure rate of component will decrease and reliability of that will increase after each imperfect maintenance. The trend implies imperfect maintenance can restore component performance to former state. We use age reduction factor $\alpha$ and effective age $e$ to describe this imperfect maintenance effect. Suppose age reduction factor $\alpha$ is constant in this paper, the component starts work at time of 0 , component fault time can be expressed as $\left(\mathrm{t}_{1}, \mathrm{t}_{2} \cdots \mathrm{t}_{\mathrm{n}}\right)$, the temporal relations between $t, \alpha$ and $e$ is shown in Fig.1. 


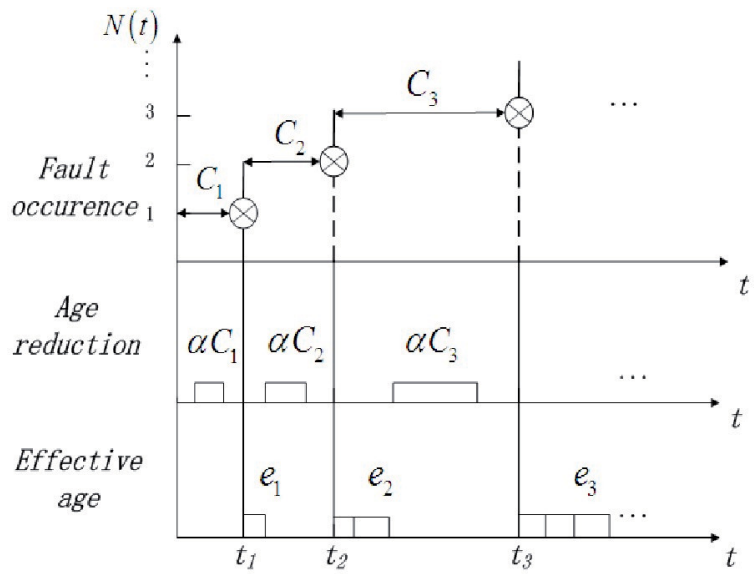

Figure 1. The temporal relation between $t, \alpha$ and $e$

The recurrence relationship between actual age $t_{i}$ and effective age $e_{i}$ can be obtained in (1) according to Fig.1:

$$
\begin{aligned}
& e_{1}=\alpha t_{1} \\
& e_{2}=e_{1}+(1-\alpha)\left(t_{2}-t_{1}\right)=(1-\alpha) t_{2} \\
& \mathrm{M} \\
& e_{i}=e_{i-1}+(1-\alpha)\left(t_{i}-t_{i-1}\right)=(1-\alpha) t_{i}
\end{aligned}
$$

Function of components under imperfect maintenance cannot restore to "as good as new". Because fault distribution function of the component is monotone increasing and the value of fault distribution function of component at $t_{\infty}$ equals to 1 , according to the description above, we can obtain (2):

$$
\frac{F_{t_{n}}-F_{t_{n-1}}}{F_{t_{\infty}}-F_{t_{n-1}}}<1
$$

Suppose $p_{n}=\frac{F_{t_{n}}-F_{t_{n-1}}}{F_{t_{\infty}}-F_{t_{n-1}}}$, we can obtain the recurrence relationship of $t_{n}$ and $t_{n-1}$ by combining (1) and (2):

$$
\begin{array}{r}
p_{n}=\frac{F_{t_{n}}-F_{t_{n-1}}}{F_{t_{\infty}}-F_{t_{n-1}}}=\frac{F\left(e_{n}\right)-F\left(e_{n-1}\right)}{1-F\left(e_{n-1}\right)} \\
F\left(e_{n}\right)=p_{n}+\left(1-p_{n}\right) F\left(e_{n-1}\right) \\
(4) \\
e_{n}=F^{-1}\left[p_{n}+\left(1-p_{n}\right) F\left(e_{n-1}\right)\right] \\
(5) \\
t_{n}=\frac{F^{-1}\left[p_{n}+\left(1-p_{n}\right)\left(F(1-\alpha) t_{n-1}\right)\right]}{(1-\alpha)}
\end{array}
$$

where $p_{n}$ is a random number from 0 to $1, t_{n}$ can be calculated by $t_{n-1}$ and $p_{n}$ according to (6).

\section{SYSTEM FAULT SAMPLE UNDER IMPERFECT MAINTENANCE}

\section{A. Complex system model}

The basic assumptions of complex system model are:
- The complex system can be divided into p layers, components in i-th layer may be combined by several sub-components in series or parallel of $(i+1)$-th layer $(0<\mathrm{i}<\mathrm{p})$.

- Suppose system fault is evoked by component fault. If a component is consisted by $\mathrm{n}$ sub-components in series. Failure rate of the component in one layer is the sum of failure rates of the $n$ components belonged to it in the next layer. At time of $t, f(t)$ is given by

$$
f(t)=\sum_{i=1}^{n} f_{i}(t), 1 \leq i \leq n
$$

- Corrective maintenance restores system or components to "partly good" condition.

\section{B. Complex system time}

According to the fault sampling method given in last chapter, the system fault time can be obtained by (7):

$$
\left\{\begin{array}{l}
t_{1}=F^{-1}\left(\beta_{1}\right) \\
t_{2}=\frac{F^{-1}\left[\beta_{2}+\left(1-\beta_{2}\right)\left(F(1-\alpha) t_{1}\right)\right]}{(1-\alpha)} \\
\mathrm{M} \\
t_{n}=\frac{F^{-1}\left[\beta_{n}+\left(1-\beta_{n}\right)\left(F(1-\alpha) t_{n-1}\right)\right]}{(1-\alpha)}
\end{array}\right.
$$

Since determination method of fault component of different reliability structure is different, the methods of fault components determination for system being series or parallel reliability structure are individually given in the follower section.

\section{Fault component determination method for series reliability structure}

When components combined by $\mathrm{n}$ sub-components in series, if one of the sub-components has fault, this component must have fault. Supposing failure rate function of this component is $f(t)$, failure rate function of sub-component is $f_{i}(t)$. Because component is combined by sub-components in series, so the failure rate of this component is the sum of failure rates of subcomponents that belong to this component, that is:

$$
f(t)=\sum_{i=1}^{n} f_{i}(t)
$$

When the component has fault, suppose sum of the failure rates of the first k sub-components is $f^{k}(t)$, that is

$$
f^{k}(t)=\sum_{i=1}^{\mathrm{k}} f_{i}(t)
$$

At time of $\mathrm{t}_{\mathrm{n}}$, the ratio of failure rate is calculated by

$$
\theta^{k}=\frac{f\left(t_{n}\right)}{f^{n}\left(t_{n}\right)}=\frac{f\left(\frac{F^{-1}\left[\beta_{n}+\left(1-\beta_{n}\right)\left(F(1-\alpha) t_{n-1}\right)\right]}{(1-\alpha)}\right)}{f^{n}\left(\frac{F^{-1}\left[\beta_{n}+\left(1-\beta_{n}\right)\left(F(1-\alpha) t_{n-1}\right)\right]}{(1-\alpha)}\right)}
$$

Giving a specified random number $\eta$, if $\theta^{k}<\eta<\theta^{k+1}$, the k-th sub-component is out of normal working condition. 


\section{Fault component determination method for parallel reliability structure}

Suppose a component is combined by $\mathrm{N}$ subcomponents in parallel, sub-components in the subcomponents malfunction can be determined according to sampling result obtained by given random numbers and fault probability at the time of $t_{n}$.

Fault state of parallel system can be expressed as (11):

$$
S=\{R / F, f(1,2 \mathrm{~L} M-1), r(M \mathrm{~L} N)\}
$$

Where $\mathrm{R}$ or $\mathrm{F}$ expresses the state of parallel system, $\mathrm{F}$ indicates fault state, $\mathrm{R}$ indicates normal state, numbers in bracket after $\mathrm{f}$ are the subscripts of fault components in the parallel system, numbers in bracket after $r$ are the subscripts of the reliable components, on the basis above, the fault state transition diagram of parallel component with $\mathrm{N}$ different sub-components can be shown in Fig.3:

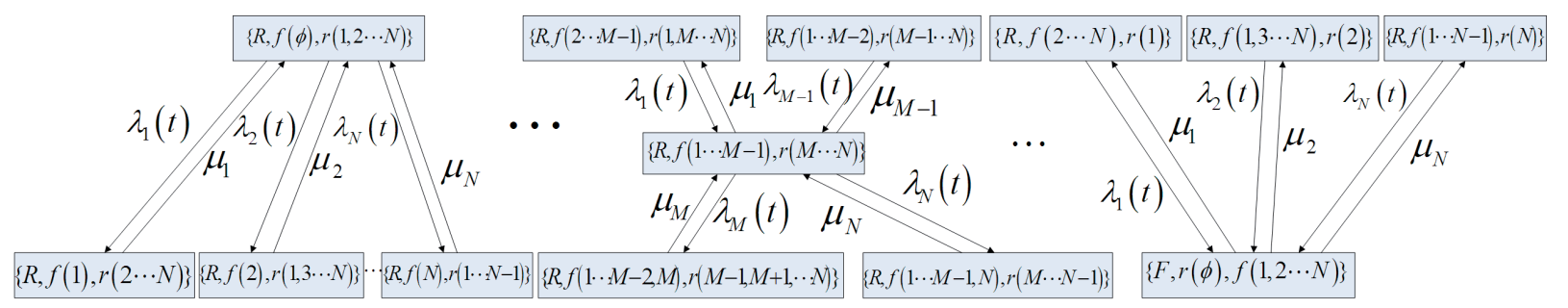
(a) $\{R, f(\phi), r(1,2 \ldots N)\}$
(b) $\{R, f(1,2 \cdots M-1), r(M \cdots N)\}$
(C) $\{R, f(1,2 \cdots N), r(\phi)\}$

Figure 2. State transition diagram of parallel component with $\mathrm{N}$ sub-components

There are $2^{\mathrm{n}}$ states in total for this parallel component, the sum of component fault state probability equals to 1 :

$$
\begin{aligned}
& \sum_{i=1}^{2^{n}} P_{S_{i}}(t)=1 \\
& \int P_{\{R, f(\phi), r(1,2 \ldots N)\}} \cdot \sum_{i=1}^{N} \lambda_{i}(t)=\sum_{i=1}^{N}\left(P_{\{R, f(i), r(1,2 \ldots i-1, i+1, N)\}}\right) \\
& \text { L } \\
& \text { L } \\
& P_{\{R, f(\phi), r(1,2 \ldots N)\}}=\frac{\sum_{i=1}^{N} \lambda_{i}\left(t_{n}\right)}{\sum_{i=1}^{N} \lambda_{i}\left(t_{n}\right)+\mu_{i}} \\
& P_{\{R, f(1,2 \ldots M-1), r(M \ldots N)\}}=P_{\{R, f(\phi), r(1,2 \ldots N)\}} \cdot \frac{\sum_{i=1}^{M-1} \lambda_{i}\left(t_{n}\right)}{\sum_{i=1}^{M-1} \mu_{i}}
\end{aligned}
$$$$
\left\{\begin{aligned}
P_{\{R, f(1,2 . M-1), r(M \ldots N)\}} \cdot\left(\sum_{i=1}^{M-1} \mu_{i}+\sum_{i=M}^{N} \lambda_{i}(t)\right)= & P_{\{R, f(2 . M-1), r(1, M \ldots N)\}} \cdot \lambda_{1}(t)+\cdots+P_{\{R, f(1,2 . . M-2), r(M-1 \ldots N)\}} \cdot \lambda_{M-1}(t) \\
& +P_{\{R, f(1 . . M), r(M-1, M+1 \ldots N)\}} \cdot \mu_{M}+\cdots+P_{\{R, f(1 . . M-1, N), r(M \ldots N-1)\}} \cdot \mu_{N}
\end{aligned}\right.
$$$$
P_{\{F, f(1,2 \ldots N), r(\phi)\}} \cdot \sum_{i=1}^{N} \mu_{i}=\sum_{i=1}^{N} P_{\{R, f(1,2 \ldots i-1, i+1, N), r(i)\}} \cdot \lambda_{i}(t)
$$

the steady state, system state probability showed in (13) can be obtained by the following rules: rate of transition from this state to other states multiply the probability of this state equals to sum rates of transition from other states to this state multiply the probability of corresponding state.
At time of $t_{n}$, according to (12) and (13), system fault

Suppose sum of component fault state probability of the first $\mathrm{k}$ states is $P_{k}=\sum_{i=0}^{k} p_{i}$.If the given random number $\alpha$ is between $\left(P_{k}, P_{k+1}\right)$, the parallel system in the k-th state, fault sub-component can be determined according to the corresponding fault information by the subscript. However, if the condition information of component derived by Markov transition process indicates this component doesn't have fault at time of $t_{n}$, the logic error happens since $t_{n}$ is component fault time, so the result should be invalid and we should restart the simulation.

\section{E. Flow chart of complex system fault sample method}

When conducting fault sample for complex system, the top-down method is used, it's referred to simulate the fault time of system and determine the fault component from system top to bottom according to reliability relationship. Having analyzed the fault component determination method for component with different reliability structure, the flowchart of fault sample method for complex system can be concluded in Fig.3: 
SPECIAL FOCUS PAPER

FAUlt SAMPLING OF COMPLEX SYSTEM UNDER IMPERFECT MAINTENANCE

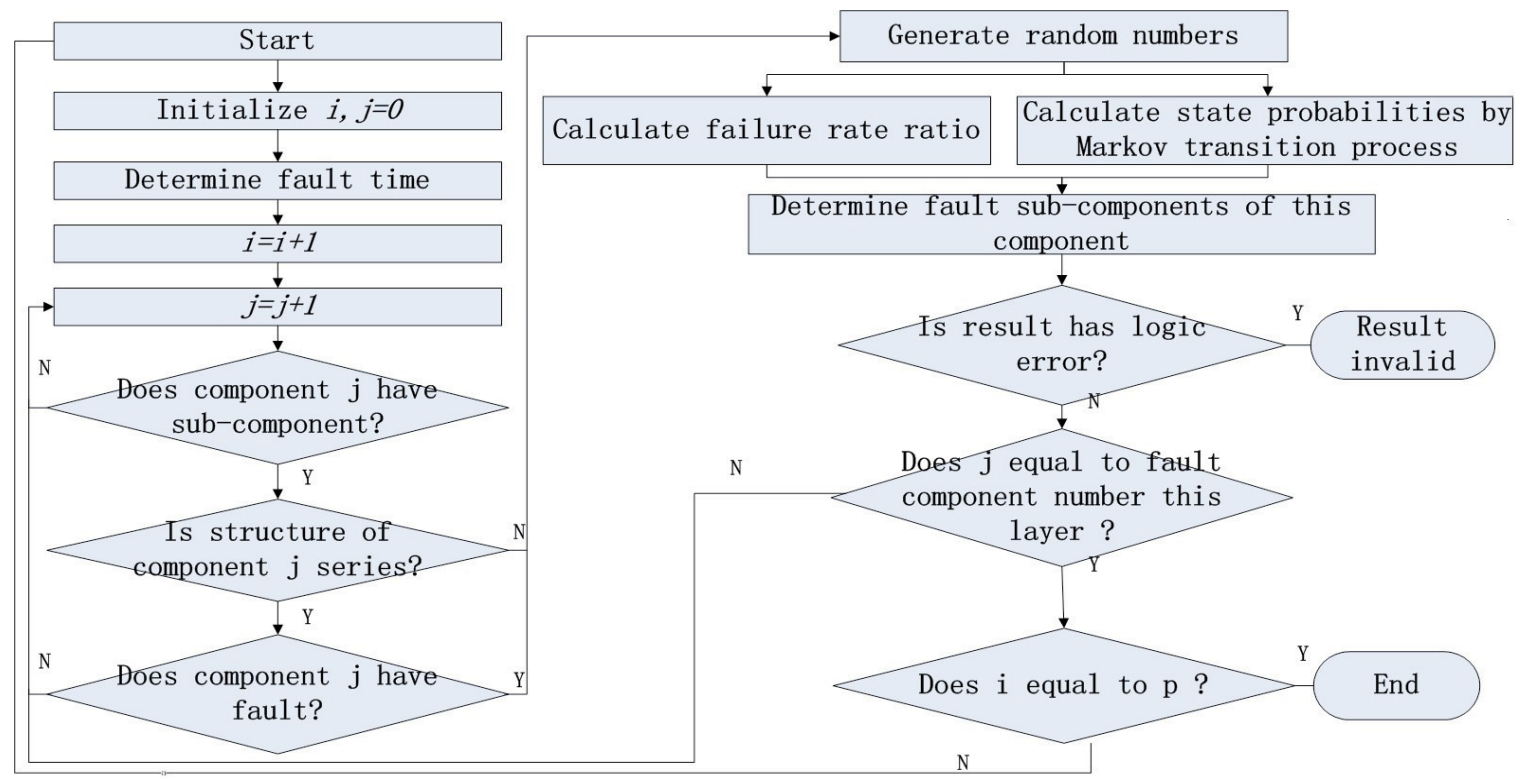

Figure 3. Flowchart of fault sample method

IV. Numerical Example

Suppose a complex system is designed as four layers, system life is Weibull distribution. The system is constructed by components in each layer shown in Fig.4: the system is combined by components in series; component 1 is combined by LRUs in parallel in the $3 \mathrm{rd}$ layer, component 2 layer is combined by series LRUs in the 3rd layer; LRU1 combined by SRU1 and SRU2 in series in the 4th layer. Failure rate ratios in each layer can be shown in Table 1, Failure rate functions of system, LRU1 and LRU2 can be shown in Table 2:

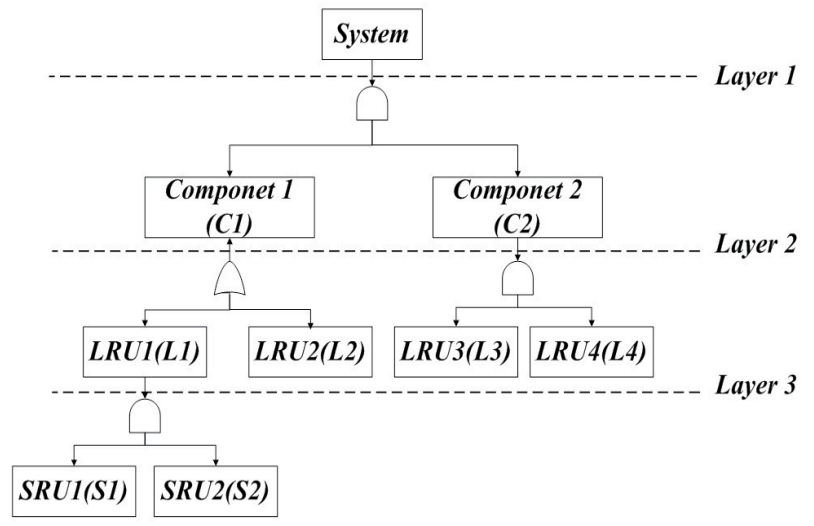

Figure 4. Complex system structure

TABLE I.

LIFETIME DISTRIBUTION FUNCTION

\begin{tabular}{|c|c|c|c|c|}
\hline \multirow{2}{*}{ Type } & \multicolumn{4}{|c|}{ Appearance } \\
\cline { 2 - 5 } & $\begin{array}{c}\text { Distribution } \\
\text { Type }\end{array}$ & $\begin{array}{c}\text { Shape } \\
\text { Paramete } \\
\boldsymbol{r}\end{array}$ & $\begin{array}{c}\text { Failure } \\
\text { Rate }\end{array}$ & $\begin{array}{c}\text { Life } \\
\text { Distribution }\end{array}$ \\
\hline System & Weibull & $m=3, t_{0}=1$ & $f(t)=3 t^{2}$ & $F(t)=e^{-t^{3}}$ \\
\hline LRU1 & Weibull & $m=2, t_{0}=1$ & $f(t)=2 t$ & $F(t)=e^{-t^{2}}$ \\
\hline LRU2 & Exp & $\lambda=2$ & $f(t)=2$ & $F(t)=e^{-2 t}$ \\
\hline
\end{tabular}

TABLE II.

FAILURE RATE FUNCTION IN EACH LAYER

\begin{tabular}{|c|c|c|}
\hline \multirow{2}{*}{ Layer } & \multicolumn{2}{|c|}{ Ratio of failure rate } \\
\cline { 2 - 3 } & $\theta_{1}$ & $\theta_{2}$ \\
\hline 2 & $\frac{t}{t+1}$ & $\frac{t+1}{t+1}$ \\
\hline 3 & $\frac{t^{2}}{t^{2}+1}$ & $\frac{t^{2}+1}{t^{2}+1}$ \\
\hline 4 & 0.5 & 1 \\
\hline
\end{tabular}

The sampling result of system fault time can be obtained according to (7) and given random numbers, suppose the system is under imperfect maintenance and $\alpha=0.5$, the sampling result can be shown in Table 3 :

TABLE III.

Fault state probability of parallel component

\begin{tabular}{|c|c|c|c|c|}
\hline \multirow{2}{*}{ Step } & \multicolumn{2}{|c|}{ Random Number } & \multicolumn{2}{c|}{ Fault Time } \\
\hline 1 & $\eta_{1}$ & 0.44 & $\mathrm{t}_{1}$ & 0.833 \\
\hline 2 & $\eta_{2}$ & 0.71 & $\mathrm{t}_{2}$ & 2.188 \\
\hline 3 & $\eta_{3}$ & 0.39 & $\mathrm{t}_{3}$ & 2.434 \\
\hline 4 & $\eta_{4}$ & 0.58 & $\mathrm{t} 4$ & 2.775 \\
\hline 5 & $\eta_{5}$ & 0.65 & $\mathrm{t} 5$ & 3.352 \\
\hline
\end{tabular}

According to random number group $\left(\eta_{1}, \eta_{2}, \eta_{3}, \eta_{4}, \eta_{5}\right)$, the ratio of component failure rate and state transition probability for the third layer, fault components in this system can be determined using top-down method, where repair rate $\mu_{1}=3, \mu_{2}=2$.In Table 4 , The state probability of component 1 can be expressed as $P_{i}(i=1,2,3,4), P_{1}$ indicates $\mathrm{P}\{\mathrm{R}, \mathrm{f}(\phi), \mathrm{r}(1,2)\}, \mathrm{P}_{2}$ indicates $\mathrm{P}\{\mathrm{R}, \mathrm{f}(1), \mathrm{r}(2)\}$, $\mathrm{P}_{3}$ indicates $\mathrm{P}\{\mathrm{R}, \mathrm{f}(2), \mathrm{r}(1)\}, \mathrm{P}_{4}$ indicates $\mathrm{P}\{\mathrm{F}, \mathrm{f}(1,2)$, 
$\mathrm{r}(\phi)\}$. Fault components determined by the proposed method at $\left(\mathrm{t}_{1}, \mathrm{t}_{2} \ldots \mathrm{t}_{5}\right)$ can be seen in Table.5.

TABLE IV.

FAULT STATE PROBABILITY OF PARALLEL COMPONENT

\begin{tabular}{|c|c|c|c|c|}
\hline \multirow{2}{*}{ Time } & \multicolumn{4}{|c|}{ Random Number } \\
\cline { 2 - 5 } & $\boldsymbol{P}_{\boldsymbol{1}}$ & $\boldsymbol{P}_{\boldsymbol{2}}$ & $\boldsymbol{P}_{\boldsymbol{3}}$ & $\boldsymbol{P}_{4}$ \\
\hline $\mathrm{t}_{1}$ & 0.24 & 0.12 & 0.54 & 0.10 \\
\hline $\mathrm{t}_{2}$ & 0.75 & 0.08 & 0.11 & 0.06 \\
\hline $\mathrm{t}_{3}$ & 0.18 & 0.34 & 0.23 & 0.25 \\
\hline $\mathrm{t}_{4}$ & 0.36 & 0.18 & 0.26 & 0.20 \\
\hline $\mathrm{t}_{5}$ & 0.61 & 0.04 & 0.26 & 0.09 \\
\hline
\end{tabular}

TABLE V.

FAULT COMPONENT IN EACH LAYER

\begin{tabular}{|c|c|c|c|c|c|c|c|}
\hline \multirow{2}{*}{ Time } & \multicolumn{3}{|c|}{ Random Number } & \multicolumn{3}{c|}{ Fault Component } \\
\cline { 2 - 8 } & $\boldsymbol{\eta}_{\boldsymbol{1}}$ & $\boldsymbol{\eta}_{\boldsymbol{2}}$ & $\boldsymbol{\eta}_{\boldsymbol{3}}$ & $\boldsymbol{\eta}_{\boldsymbol{4}}$ & $\begin{array}{c}\text { Layer } \\
\boldsymbol{1}\end{array}$ & $\begin{array}{c}\text { Layer } \\
\boldsymbol{2}\end{array}$ & $\begin{array}{c}\text { Layer } \\
\mathbf{3}\end{array}$ \\
\hline $\mathrm{t}_{1}$ & 0.67 & 0.79 & 0.65 & 0.47 & $\mathrm{C} 1$ & $\mathrm{~L} 1, \mathrm{~L} 2$ & $\mathrm{~S} 1$ \\
\hline $\mathrm{t}_{2}$ & 0.40 & 0.10 & 0.49 & 0.91 & $\mathrm{C} 2$ & $\mathrm{~L} 3$ & $\mathrm{~N}$ \\
\hline $\mathrm{t}_{3}$ & 0.88 & 0.55 & 0.86 & 0.58 & $\mathrm{C} 2$ & $\mathrm{~L} 2$ & $\mathrm{~N}$ \\
\hline $\mathrm{t}_{4}$ & 0.30 & 0.83 & 0.28 & 0.61 & $\mathrm{C} 1$ & $\mathrm{~L} 1, \mathrm{~L} 2$ & $\mathrm{~S} 2$ \\
\hline $\mathrm{t}_{5}$ & 0.15 & 0.28 & 0.54 & 0.43 & $\mathrm{C} 2$ & $\mathrm{~L} 2$ & $\mathrm{~N}$ \\
\hline
\end{tabular}

\section{CONCLUSION}

This paper has addressed several aspects in the proposed fault sample method:

- Not only exponential distribution but also other life distributions are considered in the proposed method. Imperfect maintenance is taken into account in fault sample method.

- Single component fault occurrence process subjected to imperfect maintenance is analyzed and the formula for fault occurrence occasion is given.

- When conducting the fault sample for system with complex reliability structure, fault components in the system are obtained. The Markov-state transition process is embedded into the method when system structure is parallel.

- Based on the fault sampling method mentioned above, fault occasions of complex system under imperfect maintenance are simulated and fault components in the complex system are determined in numerical case, the validity and feasibility of fault sampling method is verified

However, the simulation model still have some aspects to improve: only imperfect repair is taken into account in this paper, perfect repair and condition-based maintenance should also be included. The method should also be adapted for k-out-of $\mathrm{n}$ system in future research work.

\section{REFERENCES}

[1] Laurent Doyen, Olivier Gaudoin, "Classes of imperfect repair models based on reduction of failure intensity or virtual age," Reliability Engineering and System Safety, vol. 84, pp.45-56, Jan 2004. http://dx.doi.org/10.1016/S0951-8320(03)00173-X
[2] Tonon Fulvio, "Using random set theory to propagate epi-stemic uncertainty through a mechanical system," Reliability Engineering and System Safety, vol .85, pp.169-181, (Jan.-Mar.) 2004

[3] Yann Dijoux,. "A virtual age model based on a bathtub shaped initial intensity," Reliability Engineering and System Safety, vol .94, pp.982-989, Jan. 2009.

[4] Hoang Pham, Hongzhou Wang, "Imperfect maintenance," European Journal of Operational Research, vol. 94, pp.425-438, Oct. 1996.

[5] Lin D, Zuo M. J. and Yam, R.C.M, "Sequential imperfect preventive maintenance models with two categories of failure modes," Naval research Logistics, vol. 48 , pp172-183, Dec.2001. http://dx.doi.org/10.1002/1520-6750(200103)48:2<172::AIDNAV5 $>3.0 . C O ; 2-5$

[6] Harold S Balaban, Robert T Brigantic, Samuel A Wright, "A Simulation Approach to Estimating Aircraft Mission Capable Rates for the United States Air Force," Proceedings of the 2000 Winter Simulation Conference. Orlando, USA, pp.1035-1042. 2000 .

[7] Jiao,Z.L.Wang, "Operational availability demonstration of military airplane based on simulation," Journal of BeiJing University of Aeronautics and Astronautics, vol.32 , pp.112-116, Jan. 2006.

[8] C.Su, S.Wang, Y.Xu, "Dynamic reliability of Hydraulic system based on monte carlo simulation," Journal of Southeast University, vol.53, pp.370-375, Mar. 2006.

[9] B.H.Zhao, Y.Wang, "Research on Model and Simulation for the Military Aircraft Availability," Journal of the Academy of Equipment Command \& Technology, vol.17,pp.102-106, Feb. 2006

[10] R. M'inguez, J. M. Mart'inez, O. F. Castellanos and Ra'ul Guanche, "Component Failure Simulation Tool for Optimal Electrical Configuration and Repair Strategy Design of Off-Shore Wind Farms," OCEANS, Spain, pp.1 - 10. 2011.

[11] Marseguerra M,Zio,E and Cadini F, "Biased Monte Carlo unavailability analysis for systems with time-dependent failure rates," Reliability Engineering and System Safety, vol.76, pp11-17, Jan. 2002. http://dx.doi.org/10.1016/S0951-8320(01)00139-9

[12] Marseguerra M,Zio E, "Optimizing maintenance and repair policies via a combination of genetic algorithms and Monte Carlo simulation," Reliability Engineering and System Safety, vol. 68,pp69-83, Feb. 2000. http://dx.doi.org/10.1016/S09518320(00)00007-7

[13] Ramin Moghaddass, MingJ.Zuo, W.Wang, "Availability of a general k-out-of-n:G system with non-identical components considering shut-off rules using quasi-birth-death process," Reliability Engineering and System Safety, vol.96,pp.489-496, Mar. 2011. http://dx.doi.org/10.1016/j.ress.2010.12.001

\section{AUTHORS}

Chao Zhang is a student with the Department of Reliability and Systems Engineering, Beijing University of Aeronautics and Astronautics, Beijing, CO 100191 China (e-mail: 18810389458@163.com).

Linhan Guo is a professor and master supervisor with the Department of Reliability and Systems Engineering, Beijing University of Aeronautics and Astronautics, Beijing, CO $100191 \quad$ China (e-mail: linhanguo@buaa.edu.cn).

This research is supported by the National Natural Science Foundation of China (Grant No. 61104132, No.70901004 and No.71171008). It is an extended and modified version of a paper presented at the 2013 Chinese Intelligent Automation Conference (CIAC2013), held in Yangzhou, Jiangsu Province, China, in August 2013. Submitted 20 April 2013. Published as re-submitted by the authors 23 July 2013. 